\title{
Architectural design support for business process and business network engineering ${ }^{1}$
}

\author{
Henry M. Franken, René Bal, Harmen van den Berg, Wil Janssen \& Henny de Vos. \\ Telematica Instituut, Post Box 589, 7500 AN, Enschede, The Netherlands.e-mail: franken@telin.nl
}

\begin{abstract}
Concurrent enterprises and networks of business processes cannot function without each other. Cooperation in networks allows for faster reaction to business opportunities. Co-operation requires that the business processes and information technology (IT) systems within and between companies are well-aligned with the demands their environment puts upon them. This requires a careful and effective analysis and design of business processes from a customer-to-customer perspective. Moreover, the introduction of IT for effective business network operations and co-ordination will only function in a predictable way when one has an accurate (design) model of the interaction and co-operation in the network. Therefore a good model is essential. In this paper we show how modelling and analysis principles we developed for business process engineering can be used in business network engineering. We also introduce a visual design studio developed for this purpose. This visual design studio enables business process engineers to capture and analyse both structural and behavioural aspects of (networks of) business processes in terms of models without having to actually build these processes first. Models created with this visual design studio can be analyzed and reconfigured on the basis of various business scenarios and perspectives and/or new technological possibilities. In the same way the strategic benefit of IT for business processes and networks can be analysed and demonstrated. We furthermore discuss the additional endeavors confronted with in business network engineering projects in contrast to business process engineering.
\end{abstract}

Keywords: Business processes, business networks, business modelling \& analysis, information technology.

Biographical notes: Henry M. Franken received an M.Sc. and Ph.D. (with honours) in Electrical Engineering from the University of Twente, The Netherlands. He now work as a senior member of the scientific staff of the Telematica Instituut. He is currently manager of the acknowledged Testbed-project. His current research and consulting interests focus on applying system engineering principles to business process design and electronic commerce.

\section{Introduction}

The information society is coming of age. New electronic ways of co-operation and doing business are emerging. There is much interest in the approaches, possibilities, benefits and best practices of this new paradigm. For instance, under the $5^{\text {th }}$ Framework program for research and technological development of the European Union (1998-2002) the information society technology program will focus its key actions (new methods of work and electronic commerce) on addressing these issues in particular.

Information technology (IT) bridges time and geographic limitations and allows structuring information-intensive co-operation and work-distribution in a more flexible way. Basically, the new way of working can be envisioned as a network of distributed processes (performed by teams of distributed actors and resources) that interact as customers and servers. Such ways of working are only effectively possible (given cost and timeliness criteria) by using IT.

The interest in the strategic use of the increasing possibilities of IT has been a major management and consultancy issue in the last decade. It was concluded that the benefits of IT are only marginal if superimposed on current organisational strategy, processes and systems

\footnotetext{
${ }^{1}$ Published in the International Journal of Services Technology and Management, Vol. 1 No. 1, pp 1-14. Spring, 2000. ISSN 1460-6720
} 
$[2,17]$. Business process (re)engineering was proposed as a discipline. To really benefit, business processes and IT innovation should keep pace. The enabling factor of IT is best achieved when business processes are also innovated. Furthermore, such business process innovation can often only be realized with the introduction of this new technology. Advocated business process engineering approaches supported just that; identify, model, analyse and innovate business processes with the use of IT [2]. Given the fact that business networks function as a network of linked business processes, can we extend these approaches and make them applicable for business network engineering?

Effective business networks consist of well aligned business processes crossing inter- en intra-organisational boundaries. As with individual business processes, the business networks should respond adequately to their customers, be cost-effective and provide sound quality. This demands a careful and effective (design) analysis of the networked business processes from a customer-to-customer perspective. Moreover, the introduction of new IT for enabling effective business network operations and co-ordination will only function in a predictable way when one has an accurate (design) model of the interaction and co-operation in the network. So a good model is essential. This is accepted for the design and analysis of single processes [14]. We argue it is even more crucial for networked business processes.

This paper contributes to design support for business process and business network engineering. We introduce modelling and analysis principles for this purpose. We introduce a visual design studio supporting these principles with computer design tools. This visual design studio enables business process engineers to capture and analyse both structural and behavioural aspects of networked business processes without having to actually build these processes first (see figure 1). In the same way the potential benefit of supporting IT can be shown. Models built using this visual design studio can be analyzed and reconfigured on the basis of various business scenarios and perspectives and/or new technological possibilities. We demonstrate the applicability of these business process engineering principles to business network engineering. The research and pilot-studies for this paper were conducted for and together with leading firms and institutions in financial services in Europe (see acknowledgements).

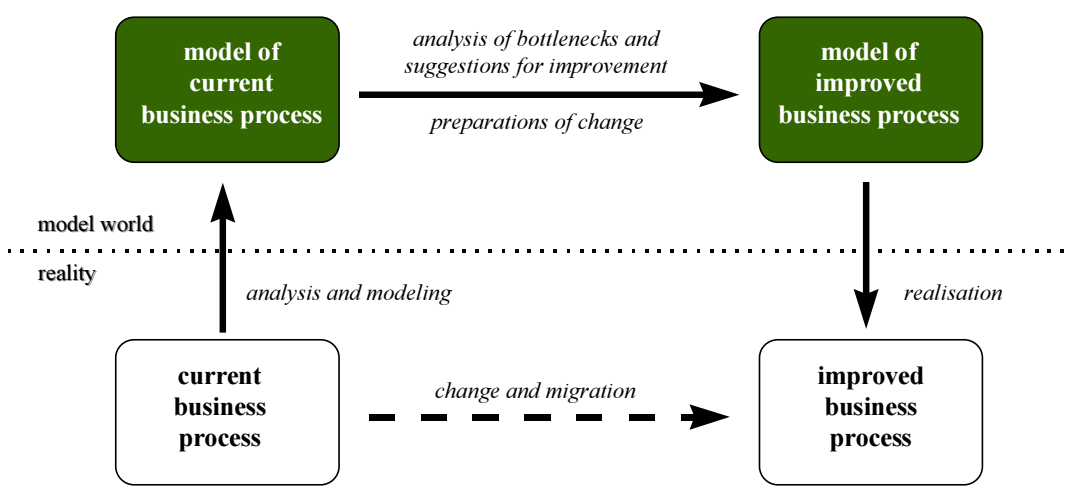

Figure 1: A model-based approach to business process change

We focus the discussion in the article to engineering principles for analysis and design of operational networked processes. It is evident that research $\&$ development and new product development projects need major knowledge management initiatives to be successful. Also strategic positioning considerations concerning which market to enter, with whom to cooperate, giving priorities to certain products and services or customer-segments, what service level agreements are offered in the end, etc. are of major importance for the actual success of networked processes. The treatment of these management issues goes beyond the scope of this paper but must be clear before even starting to analyse and design networked processes. We refer to [2] for the discussion of global steps in strategic business process innovation. 


\section{The strategic role of information technology in (networked) processes}

Popular uses today of IT-applications in information-intensive business process and network setting are supply chain systems, workflow and process management solutions, document imaging applications, call-centres and electronic commerce solutions. These applications are (to be) working together with internal information (management) systems. The Internet is more and more accepted as business infrastructure of the future, acting as the backbone for the mentioned applications.

Electronic commerce refers to electronic ways of co-operation and doing business by use of IT. Electronic commerce brings down the costs for all typical inter-business actions and makes them more effective by bridging time and distance electronically. Typical (inter- and intra-) business actions are browsing, marketing, purchasing, negotiation, contracting, delivery, invoicing, settlement and process and business network co-ordination. Moreover, IT will further give raise to the emergence of new business processes and business networks and new types of co-operations and organisational forms. Examples are (cyber) intermediaries searching for best deals and/or collecting customer information, electronic auction places, trusted third parties for notarial actions in electronic transactions and virtual networked organisations co-ordinated by advanced process co-ordination tools.

As Venkatraman [17] points out clearly, IT can be used to innovate at different levels of cooperation; e.g. localized exploitation, business network redesign and business scope redefinition. Localized exploitation of IT can reduce cost and increase speed. Such use of IT is not revolutionary and is easily copied by competitors. Internal integration of business processes crossing organisational boundaries through IT is of greater strategic importance. Such integration should be designed through the eyes of potential customers of the process. Too often, however, the focus shifts towards technical integration issues which is 'only' a necessary prerequisite. Business network redesign refers to using IT between organisations to streamline, co-ordinate and control the interlinked business processes. This may lead to cutting out certain process-parts in the network which are redundant or may lead to further specialisation of certain process-parts to meet performance and quality measures of the total network. Interoperability of organisation, processes and systems is a major challenge here. Finally, business scope redefinition is a higher level of innovation through transformation enabled by IT. Co-operating organisations reconsider what is done inside the firm (internal processes) and what is obtained new through external relationships. The latter is an activity with strategic choices and high risks.

In any case, IT should not simply superimpose on current organisational structures, processes or networks for co-operation. Simultaneously reconsidering and innovating these ways of cooperation hand-in-hand with the way to use IT, using customer service levels, costs and quality as design criteria, yield better results.

\section{Business processes and business networks}

Changes in business processes are the order of the day. New business opportunities are constantly appearing in the market place, in the form of new products, more efficient processes, networked business and alternative distribution channels made possible by IT. In addition, the demands of critical customers (effective customer response), intensified competition and changes in legislation (especially true for the financial service sector) necessitate constant innovation in business operations. In other words, flexibility is vital. Hence the question is not whether companies should modify their products and processes, but how they can do so in a responsible way.

A business process comprises the whole of activities that occur between the request of a service of product and its delivery. In short: from the customer to the customer. We 
distinguish core, support and management processes [6]. Core processes provide services to external customers, support processes provide services to internal customers (and thus contribute indirectly to services to external customers). Management processes control the core and support processes, plan the business organisation and initiate change trajectories [4].

So, (networked) business processes create products and services of value for customers. Many parties co-operate and do business together (in networks) to realize these products and services. Imagine a customer claiming car-repair based on an insurance policy. Parties such as the customer, the insurance company, the garage, car-delivery logistics providers, banks and possible intermediaries co-operate in this business transaction (see e.g. figures 2-4). The internal business processes of these companies must synchronize to effectively deliver this service.

A business network consists of the co-operation of actors in a chain to produce products and services of value for the end-customer. The network is integrally managed regarding organisation, procedures and technical systems. Business networks can be considered as horizontal integration of core processes to handle each customer engagement with guaranteed service. Vertical integration on the other hand focuses on integrating and optimizing each separate business function to achieve cost-efficiency. Indeed responsiveness, quality and cost are service parameters in the network design.

Each individual knows his or her task within the company and will aim at executing this task as efficiently as possible. However, companies are not judged by individual tasks but by the execution of business processes. These processes concern co-operations, dependencies, different roles and contributions of people, resources and information. Insight in the entire chain of activities from customer to customer will uncover bottlenecks and enables employees to anticipate and control these events themselves. This is why process improvement or redesign takes the entire chain or network as its starting point. A model of the entire chain can provide this insight (see also [6,14]).

Thus, networked business processes are linked (across internal and external organisational boundaries). To design networked business processes (and supporting IT-systems) it is essential to take the paradigm of customer-to-customer processes. Such processes need integral management functions for the entire chain (for logistics, organisational design, IT support, etc.) to co-ordinate and synchronise all activities successfully.

Business network co-ordination models for different sectors are not alike. What works for a company in packaged goods will not make sense for a company in insurance. The key to implementing useful business network co-ordination systems is to be certain that the model includes all essential characteristics of the business network so that co-ordination can be effective and performance can be enhanced and measured. Moreover, business network (re)engineering is a continuous process. Enterprises evolve, new opportunities for business and improvement appear. This demands flexible process structures.

\section{Methodology and tool support}

The Testbed Consortium [3] is currently developing a systematic approach for business process engineering. One can use this approach to analyse and prepare changes in business processes and supporting IT applications before proceeding to actual implementation. This provides one with early insight into the implications of changes, from both a business perspective (customers, completion times) and an operational perspective (costs, distribution of work, automation). The main users of Testbed are business consultants. Testbed stand for virtual test environment for business processes. The testing of business processes takes place using understandable models created for this purpose. Computer-based simulation, analysis and comparison of such models can be used as the basis for preparing changes in business processes outside the actual business operations. This reduces potential risks and the cost of 
changes in business processes. Testbed provides powerful methodologies and software tools for this purpose (see www.telin.nl/testbed). The Testbed tools and methods have been validated in practice in a large number of pilot studies in financial services. The functionality is constantly being enhanced using feedback from actual practice. In this section we describe the Testbed methodology and tool support.

\subsection{Methodology}

Testbed provides an accessible handbook as well as powerful tools. The handbook contains a systematic approach to analysing and (re)designing business processes. The computer tools in Testbed Studio support this approach. The methodological support starts with a clarification of business questions, critical success factors and change objectives. These objectives form the starting point for step-by-step modelling and analysis of current business processes. The models can be built, analysed and validated using tools. The methodology guides the systematic design of new and alternative business processes given the proposed innovation objectives. Furthermore such new models are the basis of impact-of-change analysis and a preparation of a migration, implementation and change programme. Each step is enhanced with best practices and learning experiences. See also [12] who are working on a handbook for organisational processes.

\subsubsection{Modelling support is essential for design and analysis}

One needs insight in the essence of business processes and business networks to design successful (networked) processes. This insight is also needed to set-up the requirements for the enabling IT for such inter-company co-operation. Such understanding can be achieved by modelling the essence of (networked) business processes. We have developed an architectural business modelling language with tool support for modelling, analysis and redesign functionality to get a grip on meaning of and coherence between complex intercompany business processes. We argue that in this way one can also analyse the flexibility and potential redesign opportunities into new processes and networks.

The business modelling language we developed allows to easily model the essentials of networked business processes in a clear and precise way. The modelling language enables a business consultant to present the following essential business process issues:

- who are involved (the actors);

- which activities are carried out (the behaviour);

- which data/products are involved in the activities (the items).

Figure 2 shows a simple example of networked business processes. The same modelling elements can be used to model (the requirements put on) supporting IT-sytems.

The modelling language also provides simple options for describing process roles, resources and capacities. Typical details of process activities can be added using profiles. Profiles are predefined structured data sets which can be attached to specific modelling elements. An eamples of a profile is action characterizer: who (which entity) is performing the activities, whether an activity belongs to core, support or management processes, whether the activity is performed manually, with IT support or fully automated. Other profiles concern organisation reporting relationships, process costing data or process performance. One should only attach those profiles needed for specific modelling and analysis purposes. These profiles can be used by the developed tool to functionally and quantitatively analyse and visualize the meaning of business process models. 


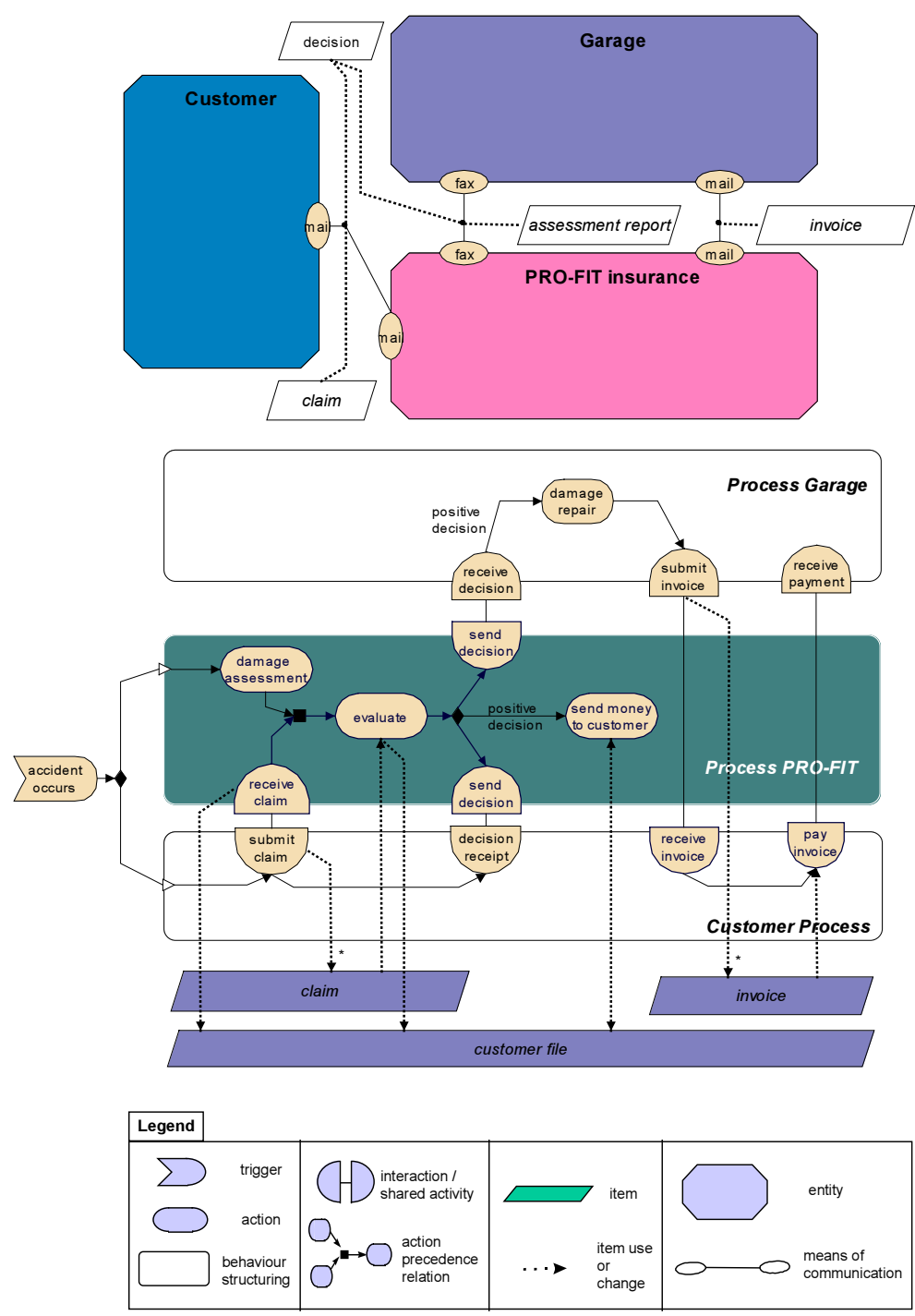

Figure 2: From top to bottom: Actors involved in claim handling and information exchange; Claim handling process; legend with meaning of modelling elements.

Testbed allows to model, analyse and redesign core and support processes. All typical business situations can be modelled and analysed precisely. Models can be made at different levels of detail. Testbed models are management instruments for guidance, planning and changes.

\subsubsection{Tool support}

Tool support is evidently needed in model-based business process engineering. The Testbedtool supports easy construction of business models. These models can be simulated (step-bystep). Simulation not only shows clearly how the business process is executed but can also be used to compare alternatives. The business consultant can also correct design errors before they cause any harm. For instance various scenarios can be analysed on a 'what-if' basis.

These scenarios can also be analysed in terms of completion times, costs and critical paths. Attaching and filling in the appropriate profiles can do this. Operations management research principles are known to be used to quantitatively compute, predict and in restricted ways optimize the performance of operational and logistic processes to achieve higher process efficiency. We integrated some of these techniques in our methodology and tool studio [9]. 
The models can be analyzed on static characteristics. The tools provide support for all the questions a business consultant has to deal with. For instance there are options for showing who performs which activities, which activities take longer than e.g. 'fifteen minutes', and which activities provide added value, etc.

In order to support business processes using for example workflow management [10] one requires rigorous analysis in advance. Incorrect design decisions can lead to the wrong kind of services or financial risks. It may then take a long time to rebuild relationships with customers and repair business processes and records. Testbed provides specific analysis support for such automation programmes in the form of model checking [8]. This tool identifies design errors in the business process models.

Models are often used to plan a migration path from the current business process to the new process. First one maps out the current situation. Then one uses this to define the essentials of the process as the basis for various potential redesigns. One can easily establish such a sequence of business models in Testbed using a repository. This will serve as a simple version management tool when phasing in changes to processes and of course as a navigation tool through the actual sequence of models. The same repository can be used at a finer granularity to save and reuse business model components (for component based model design [1]).

\subsection{Implementation}

Models can also function as a uniform specification for the actual (technical) realisation of the change trajectory. The modelling language contains an accurately defined meaning (semantics) and is thus much more than a drawing technique alone. This enables that relation between business design, implementation and co-ordination can be clear and straightforward. Testbed has developed export facilities to workflow management systems and is developing these to IT-application development environments (e.g. Icase systems) for this purpose. Basically the translation of design to implementation should be one-to-one. But given the fact that legacy applications are often coupled into new systems for business network management the design should at least be able to generate tests suites for the operational system.

\subsection{From business process engineering to business network engineering}

By structuring a model, insight is improved and the complexity remains under control. The structuring of a network of processes can take place by recognising consecutive stages in behaviour or by clustering contributions of the participating actors (within a company or a chain of companies). In this way the roles of different processes and/or parties can be clearly visualized and reconsidered. A high-level model can thus be made to determine the relationships between several parties or company departments. It is also possible is to make a more detailed description of a relevant part by elaborating its model. The models are particularly suited as management tools to illustrate, reason and evaluate the (consequences of) changes.

In the following figures we illustrate how the design concepts we developed for business process engineering can be used to business network engineering. Figure 3 shows a different design of a business network. In this case we have chosen, just for illustration purposes, to define a role for insurance intermediary to provide clear customer interfacing.

Figure 4 show the internal structure of the PRO-FIT process, illustrating how the detailing a model takes place. 


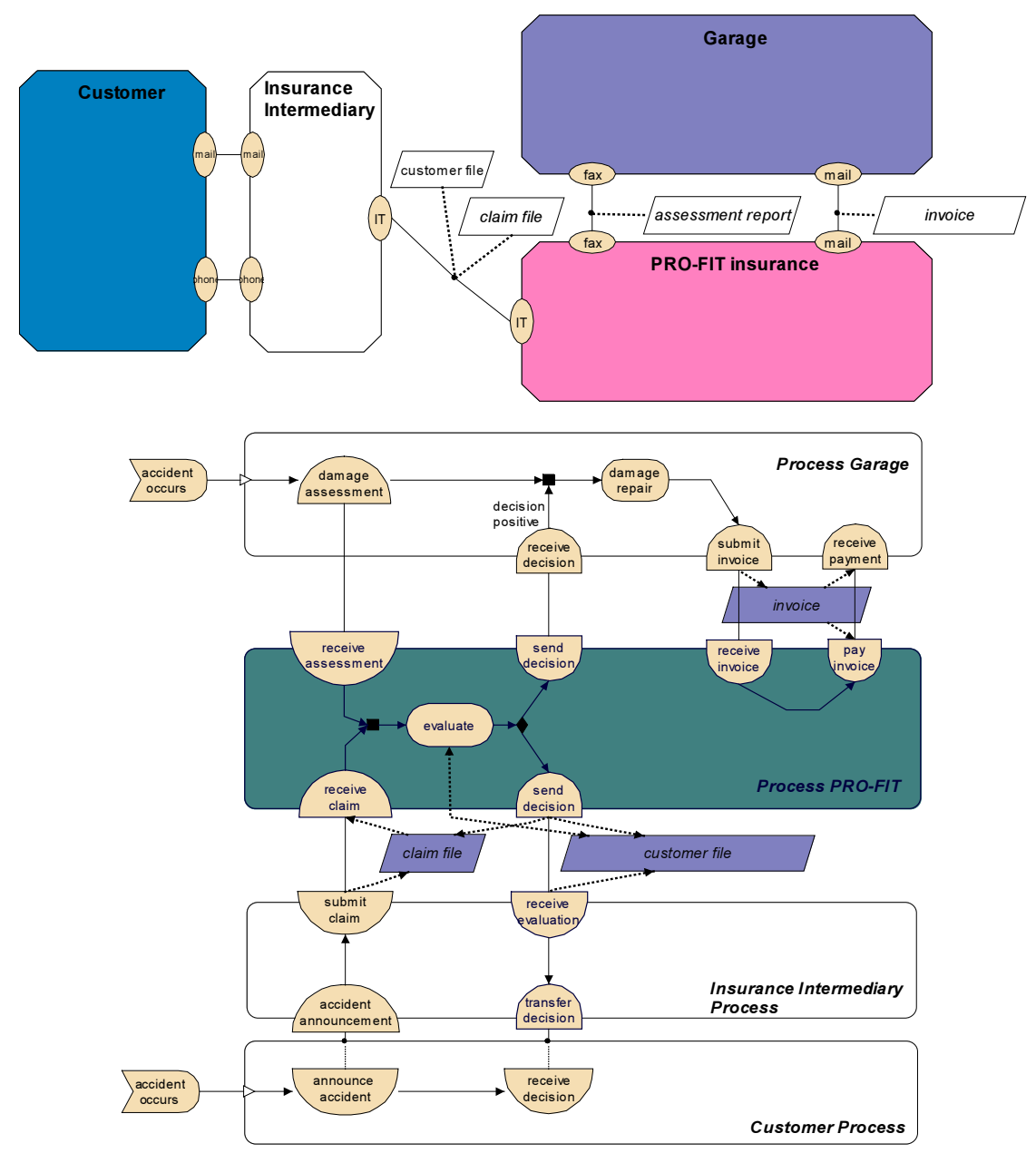

Figure 3: Shifting roles in Claim Handling

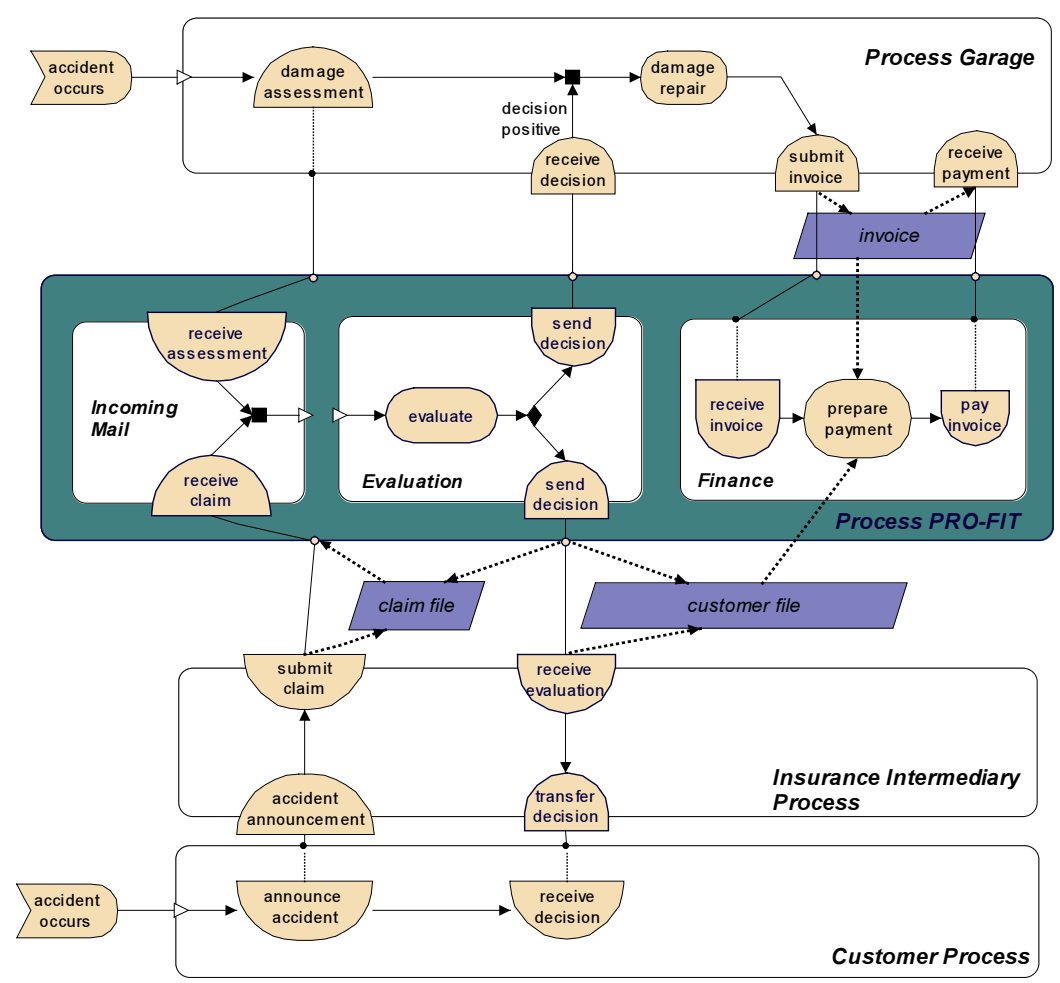

Figure 4: Detailing the internal structure of process PRO-FIT. 


\subsection{Related work}

There are numerous languages and tools available in market and academic research fields used for business process engineering. These approaches range from simulation models (e.g. Arena; [13]), workflow models (e.g. Cosa; [10]), communication protocol models (e.g. described in Petrinets) organisational communication models (e.g. based on speech-act theory), approaches stemming from information system design (e.g. Unified Modelling Language; [15]) and industrial enterprise resource planning (ERP) design and implementation (e.g. ARIS; [16]). All of these approaches are working their way up to business process and network engineering by integrating several kinds of modelling concepts and descriptive functionality to meet the diverse criteria.

We have examined these approaches for our purposes on the criteria set by the Testbedconsortium. We refer to [7] for a more detailed evaluation. These criteria are functionality, ease of use, business process engineering suitability and integral methodological and tool support. Functionality is concerned with expressiveness, structuring possibilities, analysis features and architectural suitability for business modelling. Ease of use implies that the business process modelling language should be intuitive and communicable, giving we are aiming at business analysts or business consultants to build and use models. Business engineering suitability concerns being able to design, redesign, migrate and realize systems using a sequence of modells. Furhtermore it concerns language support for component-based design and sharing of model parts. Methodological support concerns a sort of handbook with guidelines and documented approached for business process engineering. Integral tool support must go several steps futher than a simple drawing tool. Business process and business network engineering demand more extensive support to model, analyse and redesign complex models. At the time of this examination none of the above approaches statisfied the requirements set by the Testbed consortium. For this reason we proceeded to develop the Testbed approach.

\section{Additional endeavors}

Business network engineering is a greater endeavour than business process engineering [11]. We raise some questions to illustrate this point. With multiple parties involved one can question who is the boss or whether one party can overrule another and thereby disturb the functioning of the network. More so, are costs and benefits spread equally? What is the best co-ordination paradigm? The end customer expects a certain service at a certain cost but are all the partners in the chain aware of this performance/cost ratio? To meet such performance it is essential to set clear service level agreements for each process in the network. A network is as strong as its weakest link, so how trustworthy are the links? How does one manage buffers?

Finally, one can increase the profitability of a business network only by knowing the costs of the different business management models. To make design decisions there is a need for business network engineering principles relating profitability and sustainability to measurable parameters such as product cycle-time, product velocity, cash flow, number of links, number of partners, number of suppliers.

Quality management is of crucial importance to attract and keep customers. Quality in financial services refers to timeliness of services with guaranteed service levels. In business networks quality management is a great endeavour. Not only the networked customer-tocustomer core processes must be monitored and guided for proper quality. Also support and management processes within the different links of the network, which influence the core process indirectly, must ensure the desired quality benchmark. There is a great interdependence between the different links in the business network which makes quality management a major task when setting up a networked business. The whole network is more 
than the sum of the independent processes. Each process has its own responsibility, has its own service level agreement but more so is responsible for its contribution to the whole network and must react properly to dynamically changing situations and point out the consequences to other processes in the network. It is obvious that quality must be a design issue in business network (re)engineering projects. Total quality management is achieved by a portfolio of reengineering projects in which the guaranteed service levels to the endcustomer of the network is ensured in the different links of the network (without numerous double-checks on quality).

Articulation of the firm's strategy for business network (re)design is of crucial importance. This needs to be creative and clear. Is operational efficiency the most important innovation objective or does the firm go for specialization and will take on a specific process in a network. Does the firm work with several actors or a selected few? Can certain processes at the customer or supplier be overtaken or vice versa to achieve a win/win situation in the total network? Effectiveness of business process networks ultimately depends upon choosing a role and teaming business relationships with high quality business partners. These are management decisions. The presented modelling principles in this article help envision the scenario's and make the implementation path and operational characteristics of the networked processes and supporting IT systems more predictable.

\section{Acknowledgements}

The results have been realized in the Testbed-project. ABP (a large Dutch pension fund), ING Group, the Dutch Tax Department, IBM and the Telematica Instituut started the Testbed-project in April 1996. It is a major project in size (125 man-year) and impact (major companies involved). Testbed stands for virtual test environment for business processes (Franken et al., 1999) and aims at a systematic and managerial approach to realize change in business processes in the financial service sector. See also: www.telin.nl/testbed. Testbed consists of an architectural sound methodology and supporting computer tools for business process analysis, design and implementation. We thank P. Oude Luttighuis (Telematica Instituut) for his review and suggestions for improving this paper.

\section{References}

1. F. Biemans, W. Janssen, P. Oude Luttighuis, H. Schaffers, P. van der Stappen, 'Business driven design of telematics services', 5th International Conference on Concurrent Engineering, The Hague, March 1999.

2. T. Davenport and J.E. Short, 'The new industrial engineering: Information technology and business process redesign.' Sloan Management Review, Summer , 1990.

3. H.M. Franken, W. Janssen, R. Bal, H. van den Berg, 'Engineering support for business process analysis and (re)design: progress report on the Testbed project.' ACM Bulletin of Special Interest Group on Supporting Group Work, United Kingdom, vol. 19, no. 1, April 1999.

4. H.M. Franken and W. Janssen, 'Get a grip on changing business processes.', 'Knowledge \& Process Management' (Wiley), Winter 1998.

5. H.M. Franken and M.K. de Weger, 'A modelling framework for capturing business process dynamics.' Business Change and Re-engineering, Vol. 4, No. 3-4, SeptemberDecember, 1997.

6. Garvin D.A., 'The processes of organisation and management', Sloan Management Review, Summer, 1998. 
7. W. Janssen, H. Jonkers and J.P.C. Verhoosel, 'What makes business processes special? An evaluation framework for modelling languages and tools in Business Process Redesign.' In: Siau, Wand and Parsons (eds.), Proceedings 2nd CAiSE/IFIP 8.1 international workshop on evaluation of modeling methods in systems analysis and design, Barcelona, June 1997.

8. W. Janssen, R. Mateescu, S. Mauw, and J. Springintveld, 'Verifying Business Processes using SPIN', In G. Holzman, E. Najm and A. Serhrouchni (eds.), Proceedings 4th International SPIN Workshop. Report ENST 98 S 002,. Ecole Nationale Superieure des Telecommunications, Paris, France. November, 1998.

9. H. Jonkers and H.M. Franken, 'Quantitative modelling and analysis of business processes.' In: A.G. Bruzzone and E.J.H. Kerckhoffs (eds.), Simulation in industry: Proceedings of the 8th European Simulation Symposium, vol. I, Genoa, Italy, October 24-26, 1996. Society for Computer Simulation Europe, Ghent, 1996.

10. Lawrence, P. (Ed.), Workflow Handbook, John Wiley \& Sons Ltd, Chichester, UK, 1997.

11. J. Magretta, 'The power of virtual integration: an interview with Dell Computer's Michael Dell.' Harvard Business Review, March-April, 1998.

12. T.W. Malone, K. Crowston, J. Lee and B. Pentland, 'Tools for inventing organisations: Towards a handbook of organisational processes.' $2^{\text {nd }}$ International Workshop on enabling technologies for collaborative enterprises, Morgantown, April 20-22, 1993.

13. Pegden, C.D., R.R. Shannon en R.P. Sadowski, Introduction to Simulation Using SIMAN. Second ed. McGraw-Hill, 1995.

14. M. Ould, 'Business Processes, Modelling and analysis for re-engineering and improvement.' J. Wiley \& Sons, 1995.

15. Rational Software Corporation, Unified Modeling Language, Version 1.0, 1997 [Unpublished report]. http://www.rational.com/ot/uml/1.0/index.html.

16. Scheer, A.-W., ARIS - Business Process Frameworks. Springer-Verlag, 1998.

17. N. Venkatraman, "IT-enabled business transformation: from automation to business scope redefinition' Sloan management review, Fall 1995. 